\title{
A IMPORTÂNCIA DE MONTEIRO LOBATO PARA A CONSTITUIÇÃO DA LITE- RATURA INFANTOJUVENIL BRASILEIRA
}

\author{
Suelen Ribeiro de Lima David ${ }^{1}$ \\ Sonia Maria Packer Hubler ${ }^{2}$
}

\section{RESUMO}

Este artigo trata da importância da Literatura Infantojuvenil de Monteiro Lobato e tem como proposta responder à seguinte pergunta: Qual a importância de Monteiro Lobato para constituição da literatura infantojuvenil brasileira? Estipulou-se como objetivos específicos: apresentar uma breve biografia de Monteiro Lobato; identificar as principais inovações introduzidas pelo autor em relação à literatura produzida para crianças até sua época; caracterizar alguns dos personagens das obras de Monteiro Lobato para crianças. Para cumprir os objetivos propostos, buscou-se reunir informações por meio da pesquisa bibliográfica, a partir de autores como Lajolo (2000), Martinele (2014), Sandroni (2016), Kranjcina (2020), entre outros. Por meio da pesquisa realizada, foi possível identificar que as obras infantis de Monteiro Lobato foram de extrema importância para a literatura infantojuvenil brasileira, bem como a inovação que trouxe para a literatura destinada a crianças e jovens, visto que foram precursoras nesse quesito e influenciaram diversos autores brasileiros de literatura infantojuvenil.

Palavras-chave: Literatura Infantil. Monteiro Lobato. Personagens.

\section{ABSTRACT}

This Course Conclusion Paper deals with the importance of Children's Literature by Monteiro Lobato and aims to answer the following question: What is the importance of Monteiro Lobato for the constitution of Brazilian children's literatu-

'Licenciada em Pedagogia pela Faculdade UNINA. E-mail: suelenribeiro.david@gmail.com

2 Professora da Faculdade UNINA. Mestre em Linguística de Língua Portuguesa. E-mail: sonia. hubler@unina.edu.br 
re? The specific objectives were: to present a brief biography of Monteiro Lobato; identify the main innovations introduced by the author in relation to the literature produced for children up to his time; characterize some of the characters in the works of Monteiro Lobato for children. To fulfill the proposed objectives, we sought to gather information through bibliographic research, from authors such as Lajolo (2000), Martinele (2014), Sandroni (2016), Kranjcina (2020), among others. Through the research carried out it was possible to identify that Monteiro Lobato's children's works were extremely important for Brazilian children's literature, as well as the innovation that he brought to the literature aimed at children and young people, since they were precursors in this regard and influenced several authors children and youth literature.

Keywords: Children's literature. Monteiro Lobato. Characters.

\section{INTRODUÇÃO}

É comum que, ao se falar em Monteiro Lobato, as pessoas tenham um conhecimento prévio sobre o autor e automaticamente o liguem aos seus livros sobre o Sítio do Picapau Amarelo. Contudo, a grande maioria desconhece a relevância do autor para a constituição da literatura infantojuvenil autenticamente brasileira. Lobato compreendeu a criança como criança e introduziu na literatura voltada a esse público novos ambientes e personagens, valorizando o simples e comum, levando os peque nos leitores a se imaginarem nas histórias, já que os contos se passam num ambiente mais próximo da realidade deles. Além de inserir em suas histórias elementos imaginários, incorporava componentes pedagógicos, com o objetivo de ensinar e, ao mesmo tempo, divertir seus leitores. $\bigcirc$ procedimento metodológico utilizado nesta pesquisa foi a revisão bibliográfica.

\section{A IMPORTÂNCIA DE MONTEIRO LOBATO PARA A CONSTITUIÇÃO DA LITE- RATURA INFANTOJUVENIL BRASILEIRA}

José Bento Renato Monteiro Lobato, conhecido popularmente apenas como Monteiro Lobato, nasceu em Taubaté, São Paulo, no dia 18 de abril de 1882. Além de escritor, envolveu-se em muitos outros ofícios. Homem multi- 
facetário, Monteiro Lobato pode ser classificado como escritor, literário, editor, empresário, tradutor, advogado, fazendeiro, jornalista. (SANDRONI, 2016, p. 415).

Juca, como era chamado por seus familiares, era um garoto de classe alta. Seu avô era um Visconde com grande influência sobre a região de Taubaté. Edgar Cavalheiro (1911-1958), o autor da mais completa biografia de Monteiro Lobato, descreveu uma visita do Imperador D. Pedro II à província de São Paulo em 1888. D. Pedro II, nessa visita, hospedou-se na casa do Visconde, que era, de todas da região, a residência de maior porte para receber tão respeitável visita - o Visconde possuía a maior autoridade e controle na região. (CAVALHEIRO, 1962 apud MARTINELE, 2014, p. 26).

A chácara do avô foi o espaço de maiores lembranças da infância de Lobato, principalmente por possuir uma biblioteca, lugar que o encantava pelas figuras e qualidade dos desenhos, mas que, ao mesmo tempo, eram assustadoras quanto ao seu conteúdo, por não serem livros destinados ao público infantil. Martinele (2014) afirma que, a partir de cinco anos, os livros começaram a ser balbuciados com a orientação de Olympia Augusta Monteiro Lobato, que era professora de primeiras letras e mãe de Monteiro Lobato.

Com 13 anos, Monteiro Lobato vai sozinho para São Paulo prestar exames para o Instituto de Ciências e Letras, para ingressar na faculdade de Direito: "Foi reprovado em português! No final de 1896, prestou novos exames e foi aprovado." (SANDRONI, 2016, p. 416). Durante esse período, no final de 1896, aprimorou o hábito que carregou por toda vida: escrever cartas. Eram diversos destinatários, sua mãe era a principal. Nas cartas, escrevia desde suas finanças e até mesmo sobre satisfações referentes a seus afazeres e notas. (MARTINELE, 2014, p. 31).

Em 1920, Monteiro Lobato, com 38 anos, interessou-se pela literatura para crianças e começou a escrever seus livros infantis. Esse é um período de profundas mudanças no ambiente educacional brasileiro. De acordo com Martinele (2014), Monteiro Lobato inovou a temática das histórias infantis, apresentando suas próprias obras, com o lançamento de A Menina do Narizinho Arrebitado, em uma linguagem coloquial, que caracterizava a fala brasileira. Lobato foi o 
autor que percebeu que o mundo da criança era diferente daquele que o adulto via, e assim reconheceu a necessidade de produzir textos numa forma que despertasse o interesse das crianças.

Lobato foi o grande pioneiro da Literatura Infantojuvenil no Brasil. Considerado também um dos maiores revolucionários da literatura brasileira, trouxe com ele um novo olhar para seus textos, fugindo da reprodução de clássicos estrangeiros. O autor enxerga a criança com um novo olhar, e a utiliza como inspiração para sua própria literatura clássica infantil. Escreveu histórias explorando fantasias, aventuras e tudo que povoava sua imaginação. Foi pensando na criança, e a entendendo como tal, que o autor construiu seu mundo maravilhoso, onde tudo se tornava natural, mediado pelo folclore de seu povo, o que para ele, era indispensável à obra infantil (CARVALHO, 1993).

De acordo com Pereira (2010), a literatura para crianças que existia antes de Lobato seguia o mesmo padrão das traduções; não se observava o real interesse em fazer uma literatura infantil usando elementos conhecidos dentro da cultura brasileira. Lobato pensava e escrevia de forma totalmente contrária e valorizava as lendas e tradições brasileiras:

A Literatura infantil praticamente não existia no Brasil. Antes de Monteiro Lobato, os escritos extraíam dos velhos fabulários o tema e a moralidade das engenhosas narrativas que deslumbraram e enterneceram as crianças das antigas gerações, desprezando frequentemente as lendas e as tradições brasileiras para colherem, nas tradições europeias, matéria, para suas histórias. E, se pouco ou nada de original escreviam, as traduções eram também raras e irregulares, fornecendo um balanço na própria produção. Monteiro Lobato considerava criminoso não aproveitar a onda favorável para empreender de uma vez por todas a renovação da literatura infantil no Brasil (PEREIRA, 2010, p. 4).

Visto que as crianças eram colocadas em segundo plano e a sociedade pouco se importava com a linguagem usada na literatura destinada a elas, ou com temas que fossem instigar ou não esse público, era comum traduções com outras realidades, com um distanciamento de realidade e linguístico enormes. Dessa forma, as crianças não se identificavam com o que liam; eram meras produções, não continham imaginação, criatividade. (PEREIRA, 2010). 
Monteiro Lobato, com suas obras, disponibilizou às crianças brasileiras um contato mais próximo ao seu universo. Muitos de seus personagens eram baseados no folclore brasileiro, o que caracterizava o caráter nacionalista de suas histórias. Elas provocavam o imaginário das crianças, despertando ainda mais o interesse pelas obras.

Suas histórias, no entanto, também apresentavam um caráter delator, abordando fatos políticos, sociais e econômicos. O autor apresentou o meio rural de um jeito diferente, fazendo com que a maioria das pessoas deixasse de vê-lo como um espaço constituído por seres humanos ignorantes, que, por terem uma vida simples, significava que se resumia somente a trabalhar na roça e viver daquilo que a terra Ihes oferecesse. Monteiro Lobato deixa muito clara a forma de perceber o folclore, o ruralismo e o nacionalismo em seu universo narrativo (MELO e MULLER, 2017).

Conforme Zilberman (2005), Lobato utilizava, em suas histórias, a estratégia de repetir seus personagens, de forma que não precisava inventar novos personagens a cada nova aventura que escrevesse. Era somente necessário criar outras aventuras, com mistérios desafiadores, para os mesmos personagens, que sempre estavam prontos para o que viesse.

O folclore é um dos temas mais recorrentes nas obras infantis de Lobato. Nos livros O Saci e Histórias de Tia Anastácia, o folclore aparece como tema principal: Tia Anastácia constrói um elo entre o mundo racional e o mundo das superstições e crendices; Dona Benta é representada por superstições e crendices próprias, e o tio Barnabé retrata um universo enigmático de uma cultura ancestral, do folclore e dos elementos desfalecidos (MELO e MULLER, 2017).

Mesmo suas narrativas sendo de quase total fantasia, consegue-se encontrar vários ensinamentos, valores, instruções em volta de situações lúdicas que o autor cria. Lobato oferece uma identificação fácil de ser percebida por seus leitores, criando um cenário simples, uma fazenda, onde habitam personagens simples, possibilitando uma identificação expressiva entre seus leitores e suas obras. Além disso, o autor ainda apresentava sua visão a respeito da educação e da relação que as crianças deveriam estabelecer com ela (BARBOSA, 1996, p. 
85 apud MELO e MULLER, 2017).

Alguns críticos ainda destacam que os livros, além de instigarem a imaginação por meio de uma narrativa de muita criatividade, também trazem informação e conhecimentos enciclopédicos. Entretanto, as obras com caráter mais didático são marcadas por uma estruturação com elementos imaginários, com ações e diálogos extremamente envolventes.

Reinações de Narizinho é uma das obras de Lobato na qual ele apresenta elementos claros do imaginário, em que Narizinho, às margens do lago, inicia uma conversa com um peixe e o acompanha pelo Reino das Águas Claras, em um mundo escondido no fundo do mar. Torna-se um dos exemplos em que Lobato vai incluindo aos poucos suas ideias, e de como via uma maneira de escrever usando informações para instruir e educar (ESCOSTUGUY, 2006).

Um aspecto pelo qual Lobato se destacou bastante em suas obras foi a linguagem, marcada pela simplicidade. Ele usa termos habituais, já pertencentes à cultura popular brasileira, e também cria suas próprias palavras, trazendo para as narrativas várias "modernices", como: emilice, sabuguiano, pirlimpimpim. (MELLO, MULLER, 2017). O Sítio é um reino encantado, habitado por seres cuja vida mistura a realidade e a fantasia. Lobato, quando pensou no Sítio do Picapau Amarelo, criou um reino de liberdade, onde se tinha liberdade do que ser, do que fazer, de pensar e de tomar decisões. A vida no Sítio é um eterno vínculo entre o brincar e o aprender (ESCOSTEGUY, 2006).

Monteiro Lobato faz estar presente em sua Literatura Infantojuvenil, durante os anos de 1930, uma nova forma de autoeducação designada ao público infantil. Suas obras apresentavam elementos como língua portuguesa, matemática, geologia, história, fábulas, literatura e astronomia, conhecimentos que, para Lobato, eram de suma importância para a educação infantil e infantojuvenil. Ele gerava com seus personagens uma ligação entre a educação com adultos e crianças.

A Menina do Narizinho Arrebitado é um bom exemplo de obra que apresenta várias características pedagógicas, mas que, em vez de afugentar o leitor, prende-o. Por mais que seus livros continham esses elementos didáticos, o autor não tinha como motivação principal educar, sem divertir as crianças. 
(KRANJCINA, 2020).

Monteiro Lobato, com sua grande revolução e postura inovadora em relação à criança, entendia que ela é um ser inteligente e capaz de análise crítica, e não somente um adulto em miniatura, com era comum ser classificada na época. Em seu texto, o autor escreve sobre a criança "sem coleiras", concedendo a ela um papel de transformação.

Quando se pergunta à Emília, em Fábulas (1958:63), qual o segredo do Sítio, ela responde: "O segredo do Sítio, meu filho, é um só: liberdade. Aqui não há coleiras. A grande desgraça do mundo é a coleira. E como há coleiras espalhadas pelo mundo". (PEREIRA, 2020, p. 6).

Mais uma vez, por meio de suas histórias, o autor expressa como vê o mundo e como queria que ele realmente fosse, deixando explícita a importância da liberdade.

Entre todos os seus personagens, Emília é um dos mais famosos. Ela é a boneca de pano à qual Monteiro Lobato resolve dar vida em seus livros. A personagem é caracterizada por possuir uma gramática própria. Em suas aventuras, Emília oferece opções e soluções, às vezes meio atrapalhadas, para os problemas que surgem. Ela é dominadora e individualista. Lobato deu à boneca um espírito líder, diferente dos demais personagens: ela está sempre obstinada a querer saber as coisas, expor seus pontos de vista e suas opiniões.

As características inseridas no personagem de Emília por Lobato a identificam como um ser pensante, inquieto, cheio de perguntas e perturbador. Mas uma boneca livre, dona de si e de seus atos. Uma boneca que está sempre à procura de mais conhecimento, pelas experiências adquiridas através de cada inquietação, de alguém que quer sempre saber mais. (NUNES, 2004).

Outro personagem admirado pelos leitores é o Visconde, um sabugo de milho, cujo "figurino é composto pela cartola, bengala e fraque, condensando uma ostentação da forma de vestir das elites brasileiras tradicionais". (SANTOS, 2010, p. 45).

O sabugo tem o conhecimento científico vivo dentro de si, contrapondo-se aos outros personagens do universo lobatiano em relação ao saber popular, 
mitos e crendices. Visconde é muito inteligente, considerado o cientista do Sítio. Mas todo o seu conhecimento advém de livros que ele "devorava", por isso entendia sobre qualquer assunto que surgia. (NUNES, 2004).

O saber científico do Visconde é sempre valorizado e usado como um meio para resolver os problemas que surgem nas aventuras escritas por Lobato em seus livros infantis.

Ao mesmo tempo em que, em suas histórias, Monteiro retrata seus personagens como "crianças-modelo", sem dispensar suas características de infância, atribui a eles sua vontade de mudar o método antiquado e tradicional. Essa vontade ele expressou em muitas de suas obras, mas em sua literatura para as crianças enfatizou de forma mais incisiva. (MAJOLO, 1985 apud SANTOS, 2011, p. 100).

Tia Anastácia é a cozinheira do Sítio, mas isso não impede essa personagem de estar envolvida nas aventuras da turma. Ao contrário dos outros personagens que possuem algum saber específico, ela é marcada pela sabedoria que vem de sua vida na prática do dia a dia: tudo que sabe foi através de experiências que viveu. Mas, ao contrário do que possa parecer, essas experiências de vida são muito valorizadas nas aventuras do Sítio. Mesmo a personagem estando em uma figura de empregada negra e mulher, Lobato, em suas obras, faz estar presente o respeito às diferenças sociais, raciais e culturais. E ele ainda deixa nítido essa valorização: "Tia Anastácia, essa é a ignorância em pessoa. Isto é, ignorante, propriamente, não. Ciência e mais coisas dos livros, isso ela ignora completamente. Mas, nas coisas práticas da vida, é uma verdadeira sábia." (LOBATO, 1972, p. 98 apud NUNES, 2004, p. 220). O conhecimento de Tia Nastácia não é tomado como algo inferior aos outros presentes nas histórias; através desse conhecimento o autor ainda mostra uma valorização ao conhecimento popular no processo de aprendizagem das crianças. (NUNES, 2004).

Em seu livro Caçadas de Pedrinho, em duas passagens, Tia Nastácia é comparada a animais e, por isso, foram apontados supostos conteúdos racistas pelo Conselho Nacional de Educação (CNE). (NEVES e ZAGANELLI, 2016).

Alguns críticos declararam que a obra poderia disseminar o racismo. Além de que, através de sua personagem negra, muitos poderiam se sentir ofendi- 
dos, por se verem representados por ela nas histórias. As crianças, que são seu público-alvo, se não tivessem discernimento, sabendo diferenciar o que é certo e errado, poderiam se sentir atingidas por essas questões. Mas, por outro lado, há que se ressaltar também a livre expressão e a liberdade que o autor tem ao produzir seus livros, o que é garantido na Constituição, segundo Art. $5^{\circ} \mathrm{IX}$, que afirma: "é livre a expressão da atividade intelectual, artística, científica e de comunicação, independentemente de censura ou licença". (CRFB,1988). (NEVES e ZAGANELLI, 2016).

Embora essa questão não seja tema deste trabalho, é importante destacar que Lobato nasceu em 1882, época em que o Brasil estava se livrando da escravidão. Vale ressaltar que suas obras nas quais apareciam esses estereótipos sobre os negros foram escritas em 1920, período em que foi instaurada a crise econômica e política do sistema oligárquico (República Velha). Nesse tempo, esses estereótipos eram defendidos pela sociedade, já que os negros eram vistos como aqueles que deviam se submeter aos brancos. (BRAGA et al., 2017).

Ainda sobre os personagens, deve-se fazer referência à Cuca, uma bruxa com corpo de jacaré, com cabelos loiros, pertencente ao folclore brasileiro. Essa personagem tem a grande responsabilidade de deixar muitas crianças desobedientes em alerta. Em suas histórias, Monteiro faz duas descrições físicas sobre a personagem. A primeira Cuca é descrita como um ser que "tinha cara de jacaré e garras nos dedos como os gaviões. Quanto à idade, devia andar para mais de três mil anos. Era velha como o tempo" (LOBATO, 2016, p. 157). E, em outra descrição, através de Narizinho: "Foi assim, eu estava com Emília debaixo da jabuticabeira. De repente, uma velha, muito velha e coroca, aproximou-se de mim com um sorriso muito feio na cara" (LOBATO, 2016, p. 184).

Fica evidente que, em cada personagem, Lobato soube inserir um tipo de conhecimento específico. Cada conhecimento é valorizado, até mesmo os que não têm origem científica não são vistos como algo inferior. Lobato valoriza até conhecimentos que se caracterizam como mito.

Monteiro Lobato oferece em suas obras infantis o que sabia fazer de meIhor: "sua irreverência, suas histórias criativas e emocionantes, seu conhecimen- 
to instigador, seus personagens imprevisíveis, sua eterna mistura entre o real e o imaginário e sua crença na liberdade". (ESCOSTEGUY, 2006, p. 5).

\section{CONSIDERAÇÕES FINAIS}

A presente pesquisa, por meio da revisão da literatura, buscou determinar a importância de Monteiro Lobato para constituição da Literatura Infantojuvenil brasileira.

Antes de iniciar a escrita de seus livros infantis, por volta de 1920, o autor fez uma análise dos textos destinados à leitura infantil de sua época e demonstrou descontentamento com seus conteúdos e sua qualidade gráfica. Assim sendo, começou a produzir livros com características bastante diversas das que eram comuns naquele tempo.

Monteiro Lobato soube reconhecer a singularidade das crianças e, para seduzi-las a lerem seus livros, utilizou elementos que eram pertencentes à infância, como a ludicidade e a imaginação. Mas, ao mesmo tempo, reconhecia o poder que os livros tinham de educar através das histórias. Não concordava, contudo, em imprimir regras e valores sociais que poderiam transformar a criança em pequenos adultos. Ao contrário disso, sua forma de educar em seus livros infantis era perpassada por conteúdos científicos, que, para ele, eram considerados muito importantes à criança. Por isso, decidiu escrever livros carregados de brincadeiras, imaginação e fantasia, porque, dessa forma, se tornariam mais interessantes e significativos para seu público leitor.

Os conteúdos científicos inseridos em suas histórias tinham relação com a vida social do leitor, permitiam uma atuação na vida prática científica de forma consciente. Dessa forma, o autor buscava educar a criança, para que ela tivesse um conjunto de conhecimentos que realmente a auxiliasse a resolver problemas vividos em seu dia a dia. 


\section{REFERÊNCIAS}

Braga, Mirian. et al. A LINGUAGUEM LOBATEANA E SUA CO-RELAÇÃO COM A SOCIEDADE: RETRATO OU VOZ? III Seminário Científico da FACIG, Sociedade, Ciência e Tecnologia. 9-10. novem. 2017. Disponível em: file:///C:/Users/Windows/Downloads/ 389-1495-1-PB.pdf Acesso em: 28 out. 2020.

CAMPOS, André Luiz Vieira de. A República do Picapau Amarelo: Uma leitura de Monteiro Lobato. São Paulo: Martins Fontes, 1986. 175 p.

ESCOSTEGUY, C.C. Literatura de Monteiro Lobato. Canoas RS, 2010. Disponível em: https://editora.pucrs.br/edipucrs/acessolivre/anais/CILLIJ/praticas/Literatura_de_ Monteiro_Lobato.pdf Acesso em: 01 set. 2020

KRANJCINA, Stefania. Monteiro Lobato e a Literatura infantil brasileira. 2020. Tese (Mestrado em Letras), Universidade de Zagred. Zagreb.

LOBATO, Monteiro. O Saci. 3 ed. São Paulo: Biblioteca Azul, 2016.

MELO, Denilza, MULLER, Hofélia. Monteiro Lobato e o sítio do pipapau amarelo nas práticas pedagógicas de alfabetização: a travessia histórica de 1930 ao universo contemporâneo. 2017. Universidade Estadual de Goiás - UEG - Câmpus Posse. Goiás.

NEVES, Júlia; ZAGANELLI, Juliana. O RACISMO NA OBRA DE MONTEIRO LOBATO. rdl- Rede Brasileira Direito e Literatura, 2016. Disponível em: file://C:/Users/Windows/ Downloads/206-645-1-PB\%20(1).pdf Acesso em: 10 out. 2020.

NUNES, L.A. A literatura infantil de Monteiro Lobato e o ideário escolanovista. Revista de Iniciação Científica da FFC, v. 4, n. 2, 2004. Disponível em: file://C:/Users/ Windows/Downloads/94-Texto\%20do\%20artigo-337-1-10- 20041126\%20(3).pdf Acesso: 22 set. 2020

PEREIRA, Maria. A Barca de Gleyre, de Monteiro Lobato: origens da literatura infantil brasileira. $2010.32^{\circ}$ Congresso internacional de IBBY. Universidade do Estado do Rio de Janeiro. Rio Janeiro.

SANDRONI, Luciana. Reinações de Narizinho. $3^{\circ}$ Ed. São Paulo: Globo, 2016.

MARTINELE, L. Monteiro Lobato e a educação: da crítica à produção de uma nova literatura infantil brasileira. Dissertação (Pós-graduação em Educação) - Universidade Estadual de Maringá. Maringá, 2014. 
SANTOS, Elisângela. As personagens infantis lobatianas formando um brasil futuro. 2010 UNESP- Universidade Estadual Paulista. Paraíba

SANTOS, Elisângela. Monteiro Lobato e seis personagens em busca da nação. Ed. Unesp, 2011.

ZILBERMAN, Regina. Como e por que ler a literatura infantil brasileira. Rio de Janeiro: Objetiva, 2005. 